\title{
AVALIAÇÕES EXTERNAS NAS ESCOLAS ORGANIZADAS EM CICLOS: UMA ESQUIZOFRENIA NO ESPAÇO EDUCACIONAL
}

\author{
Andrea Rosana Fetzner \\ Nathalia Santos Corrêa da Silva ${ }^{(*)}$
}

Este estudo parte da observação de que a enturmação escolar em ciclos foi concebida como uma possibilidade de questionar a lógica escolar predominantemente excludente e seletiva, em aspectos que se referem à formação social decorrente das formas de produção no mundo moderno, que instituíram processos de aprendizagem propedêuticos e artificiais (evidentemente mais rápidos), nos quais a organização seriada se insere para controlar a velocidade de aprendizagem do conhecimento necessário à mão de obra que atuará na produção hierarquizada e fragmentada (FREITAS, 2003). Nesse sistema, a avaliação serve para selecionar aqueles que dominam determinados conhecimentos, permitindo que avancem, e para excluir aqueles que não aprendem. Nos ciclos, entretanto, todos os estudantes permanecem na escola, o que denuncia a lógica excludente que constituiu historicamente a instituição escolar, exigindo tratamento pedagógico adequado e avaliações pautadas em novas relações sociais (idem, 2003). Dentro dessa perspectiva, os ciclos constituem parte de um projeto de democratização da escola pública.

No que se refere às avaliações externas, será desenvolvido o argumento de que estas se encontram "em confronto com propostas de democratização da escola pública" (ESTEBAN; FETZNER, 2015, p. 75). Segundo o estudo aqui apresentado, coexistem no espaço escolar: a proposta de enturmação escolar em ciclos, fundamentada na priorização de experiências definidas por Paulo Freire (2008a) como libertadoras, pois dirigidas à compreensão crítica e transformadora da realidade, o que passa pela humanização, solidariedade e formação integral do estudante; e a lógica das avaliações externas, pautada por um processo de coerção, certificação e exclusão das dinâmicas escolar, socioeconômica e cultural daqueles estudantes que não correspondem ao modelo idealizado (ESTEBAN; FETZNER, 2015).

Em vista disso, abordar as avaliações externas nas escolas em ciclos torna-se urgente, sobretudo ao se observar que com o Programa Nacional Alfabetização na Idade Certa (PNAIC), lançado em agosto de 2012, todas as escolas brasileiras, atendendo as Diretrizes Nacionais para o Ensino Fundamental de 9 Anos (RESOLUÇÃO 07, 2010), passaram a ter os três primeiros anos de

\footnotetext{
${ }^{(*)}$ Andrea Rosana Fetzner. Professora associada à Universidade Federal do Estado do Rio de Janeiro (UNIRIO). Nathalia Santos C. Silva. Mestre em Educação pela Universidade Federal do Estado do Rio de Janeiro (UNIRIO).
} 
escolaridade organizados sob a forma de "um bloco pedagógico ou um ciclo sequencial não passível de interrupção" ( $\$ 1^{\circ}$, do inciso III, do art. 30). O Programa que, por um lado, veio a fortalecer a organização em ciclos, por outro, também fortaleceu as avaliações externas, uma vez que instituiu a Provinha Brasil e a primeira avaliação externa para o terceiro ano de escolaridade (BRASIL, 2018).

A esta vivência, na sala de aula, de ações oriundas de políticas com princípios e fins tão diferentes, chamamos de esquizofrenia no espaço educacional: propostas antagônicas em suas concepções, as quais os docentes são levados a servir. Stephen Ball (2010), já se referia ao termo ao analisar a tensão a que se submetem os docentes, pela falta de sentido das ações cotidianas a que estão subjugados por conta do gerenciamento que busca a performatividade, com o objetivo de satisfazer o mercado.

Este trabalho é apresentado com o objetivo de contribuir no entendimento do conflito entre a organização escolar em ciclos, na sua vertente comprometida com a democratização da educação, humanização e solidariedade, e as avaliações externas, orientadas pela mensuração e controle. Apresentam-se, aqui, alguns dos conflitos políticos, teóricos e pedagógicos dessas políticas.

Trata-se de uma pesquisa qualitativa que partiu da revisão de documentos referentes à instituição dos ciclos na rede municipal estudada, visando explicitar a forma como estes e a avaliação são concebidos; realizou a revisão bibliográfica dos fundamentos teóricos que sustentam as duas políticas e dialogou com profissionais da Secretaria Municipal de Educação - SEMED e com professores que atuam em escolas organizadas em ciclos, mas subordinadas às avaliações externas. Este trabalho está apresentado de forma a explicitar o conflito entre os ciclos e as avaliações externas, o contexto de implementação dos ciclos em Nova Iguaçu e, por fim, as tensões entre as práticas avaliativas em ciclos, no mesmo município, e as avaliações externas.

\section{CICLOS E AVALIAÇÕES EXTERNAS: CONFLITOS POLÍTICOS E TEÓRICOS}

A análise das produções de autores que se dedicam ao estudo dos ciclos, como Andrea Fetzner (2008), Luiz Carlos de Freitas (2003), Miguel Arroyo (2007) e Vítor Paro (2003), permite perceber que os ciclos constituem uma proposta de organização escolar, no ensino fundamental, que prioriza o agrupamento etário com a finalidade de potencializar o desenvolvimento cognitivo, social e afetivo da criança e do adolescente, visando um conjunto de práticas curriculares, avaliativas e didáticas voltadas a contemplar as especificidades de cada estudante, sem as rupturas e seleções 
que, na organização seriada, acabam por excluir da escola aqueles que não evidenciam determinada parcela de conteúdos exigidos por cada etapa.

O segundo eixo de análise proposto por este estudo, as avaliações externas, podem ser caracterizadas como uma forma de avaliação a ser realizada por pessoas que não estão diretamente ligadas com o objetivo do processo educativo, nem com os estudantes, tendo como finalidade apresentar um diagnóstico de amplas amostras de sujeitos ou, ainda, selecioná-los. Com isso, as avaliações externas costumam centrar-se na comprovação de competências muito delimitadas (MACINTOSH, 1990 apud SACRISTÁN; GÓMEZ, 1998, p 318)

Com a institucionalização das avaliações externas em todo o Brasil, elas passam a ocupar o centro do debate educacional, suscitando implicações aos currículos e, consequentemente, às práticas avaliativas desenvolvidas em sala de aula. Esteban e Fetzner (2015) alertam quanto ao aprisionamento curricular que causam, reduzindo o conteúdo escolar ao treinamento da leitura, da escrita e do cálculo. Como consequências indicadas pelas autoras, têm-se o arrefecimento da função social da escola, com abordagens mecânicas que, inibindo o espaço para reflexão, privilegiam o treinamento para as provas, colocando a boa classificação nos testes como objetivo fim de todo o processo.

O discurso em defesa da avaliação externa destaca a necessidade de avaliar o trabalho que se realiza nas escolas para garantir a qualidade do ensino, como consequência, responsabiliza os docentes pelos resultados obtidos e, ao publicizar as médias das escolas, induz as famílias à procura de melhores escolas. Em 2006, Andrea Krug identificava a existência de duas propostas para a educação no cenário mundial: as de cunho neoliberal e as de cunho progressista, diferenciadas entre si pela concepção que carregam sobre a função da escola. Em síntese, a autora situava que, nas propostas neoliberais, a missão da escola é fazer com que os estudantes se tornem trabalhadores melhores, por meio do acesso ao treinamento de capacidades básicas para leitura, escrita e cálculo. A forma de controlar o serviço educacional oferecido (que necessariamente não precisa ser oferecido pelo Estado), são as políticas de avaliação e controle, entre elas, a avaliação de desempenho do estudante. A ideia é que, sob o argumento de justiça, a avaliação externa possa controlar: (1) o conteúdo ministrado (assegurando o acesso dos estudantes ao conteúdo considerado básico por alguém); (2) o desempenho dos estudantes; e (3) o desempenho dos professores ao ensinar. A divulgação dos resultados das avaliações seria um estímulo às escolas para que se esforcem em oferecer um ensino melhor, aos professores para que ensinem igualmente melhor e às famílias dos estudantes para que procurem as melhores escolas, o que se configura, por fim, em uma política de responsabilização. Assim, as avaliações externas filiam-se, por princípio 
(responsabilizar as pessoas e não o Estado), concepção (a competição e o sistema meritocrático como mobilizadores de uma melhor sociedade) e resultados (competição entre escolas, professores e estudantes pelas melhores colocações) às políticas de cunho neoliberal.

Ainda de acordo com Krug (2006), as propostas progressistas, por sua vez, expressam preocupações com a democratização da educação, a qual se daria pela necessidade de acesso à escola, reconhecimento cultural e intelectual dos estudantes e compromisso com a formação para uma sociedade melhor para todos. Esta sociedade melhor não seria fundamentada no mérito pessoal, promovido por meio da competição, mas na justiça social, na afirmação de direitos, na solidariedade. O Estado seria um instrumento de promoção desses valores. Nesse sentido, a abordagem dos conteúdos seria por meio das linguagens, das práticas sociais e das questõesproblema vivenciadas pelos estudantes, de forma que o conteúdo escolar fosse orientado pelas necessidades identificadas na realidade escolar. Entre as questões mais instigantes das propostas de democratização da educação, está a ideia de que todo ser humano é capaz de aprender e que, portanto, a reprovação escolar não é necessária. A esse respeito, Paro (2003) denuncia a reprovação enquanto um ato de renúncia à educação e afirma os ciclos, por constituírem uma forma de organização escolar que não admite as rupturas próprias do regime seriado, como medida pedagógica apropriada à criação de uma nova escola, que tem em sua estrutura a busca contínua do aprendizado e não a reprovação. Nessa perspectiva, os ciclos enquanto política pública comprometida com uma escola menos excludente e seletiva, estão ligados às propostas transformadoras e progressistas (FREITAS, 2003).

Em uma proposta de organização em ciclos, a avaliação é um processo que precisa ser coletivo, não classificatório, uma vez que busca acompanhar não apenas como cada estudante vem se desenvolvendo (por meio de instrumentos e registros que visibilizem os processos individuais), mas também como o trabalho coletivo da escola tem sido realizado, considerando a necessidade de educar na vivência de uma educação democrática. A função dessa avaliação seria melhorar o processo, com todos e para todos, sem colocar as famílias e os estudantes a concorrerem por determinadas escolas ou professores a concorrerem por prêmios oferecidos como forma de bonificar os melhores classificados nas avaliações externas.

A coexistência da política de ciclos e das avaliações externas na escola acaba por evidenciar a indução de uma "esquizofrenia" no espaço educacional, caracterizada, tal qual no distúrbio psíquico, pela desordem do pensamento em uma mente dividida, no caso em análise, em práticas divididas, dirigidas a intencionalidades diferentes. Ou seja, o docente submetido simultaneamente às duas políticas, acaba sendo obrigado a atuar sob a égide de concepções educacionais cujos 
objetivos, para serem alcançados, exigem ações distintas ou a prevalência de uma em detrimento da outra.

Dentro dessa análise, deve-se observar que o PNAIC agrupa políticas que têm origens e finalidades diferentes, pois apresenta a discussão dos ciclos como forma de democratização da educação escolar, como a melhor maneira de organizar as crianças na escola, o currículo e a avaliação e, ao mesmo tempo, estimula a aplicação das avaliações externas, que têm sua origem e finalidade em perspectivas neoliberais.

As avaliações externas são propostas pelo PNAIC para fazer um acompanhamento com a produção de um diagnóstico de chegada e partida no início e no final do segundo ano do ciclo de alfabetização, assim como ao final do terceiro ano do ciclo. Ocorre que as avaliações externas servem a propósitos que não se resumem a um acompanhamento da política dos ciclos. Conforme demonstrado por Ravitch (2011) e exaustivamente por Freitas (2012), as avaliações externas geram efeitos que provocam a desqualificação da escola pública, enfraquecem o sistema público de ensino e promovem a desigualdade dentro do próprio sistema. A abordagem educacional de perspectiva libertadora, como se orientam os ciclos, ao menos em determinado contexto histórico no Brasil, exige liberdade para que sejam os docentes a definirem as necessidades, os conteúdos, as situaçõesproblema a serem trabalhadas e os executores da avaliação de perspectiva emancipatória (SAUL, 2006), porque comprometida com a melhora dos processos oferecidos sem cogitar-se provas padronizadas e classificatórias. Nessas propostas, as avaliações externas, se admitidas, podem gerar (como acontece com frequência), erros de avaliação e destruição de um trabalho integrador (na experiência e compreensão dos processos de cada estudante) e coletivo (da escola sobre seu trabalho).

Destaca-se que, para além da padronização e da classificação, as avaliações externas apresentam um efeito ainda mais danoso, pois a partir delas, os sistemas de ensino tendem a reduzir seus programas à aplicação de mais testes preparatórios, o que provoca o gasto de somas vultosas de recursos que deveriam ser endereçados para a melhoria efetiva do ensino, não ao aumento de pontuações em metas irrisórias (PARO, 1999).

No Brasil, atualmente, essas metas são estabelecidas pelo Índice de Desenvolvimento da Educação Básica - Ideb ${ }^{1}$, índice sobre o qual se deve manter elevado nível de monitoramento, sob o risco de sansões políticas (desqualificação da escola frente à comunidade educativa e

\footnotetext{
${ }^{1}$ O Índice de Desenvolvimento da Educação Básica (Ideb), criado pelo Inep em 2007, é calculado a partir dos dados sobre aprovação escolar, obtidos no Censo Escolar, e médias de desempenho nas avaliações do Inep, o Saeb - para as unidades da federação e para o país, e a Prova Brasil - para os municípios (BRASIL, 2018).
} 
desqualificação de redes inteiras, mediante o ranqueamento nacional) e econômicas (há redes que oferecem gratificações em dinheiro para os professores das escolas que alcançam as metas, portanto, as que não alcançam, têm prejuízo econômico). Essa perspectiva é confirmada pelo Ministério da Educação - MEC quando afirma que "o Ideb funciona como um indicador nacional que possibilita o monitoramento da qualidade da Educação pela população por meio de dados concretos, com o qual a sociedade pode se mobilizar em busca de melhorias." (BRASIL, 2018).

Portanto, a vigilância que a sociedade passa a exercer sobre os índices obtidos nas avaliações externas, dentro desta análise, se materializa em políticas locais (municipais e estaduais) que impõem às unidades escolares o dever de adotar medidas rigorosas de controle sobre suas práticas curriculares, avaliativas e de gestão, de modo a alcançarem as metas formuladas pelas organizações internacionais para os países periféricos. Nesse sentido, Almerindo Janela Afonso (2009) afirma que as organizações internacionais e supranacionais, tais como a Organização para a Cooperação e o Desenvolvimento Econômico (OCDE); União Europeia (EU); Banco Mundial BM e Organização Mundial do Comércio (OMC), ao menos nos países capitalistas ocidentais, foram impondo políticas de avaliação, prestação de contas e responsabilização que se sobrepõem às concepções político-ideológicas dos governos, situando-se acima das realidades culturais, econômicas e educacionais nacionais. "Esta tendência, entre outras consequências, tem aumentado a eficácia legitimadora destas políticas, tornando mais difícil desocultar os interesses, demandas e funções que lhe subjazem." (idem, p.17).

Segundo o Instituto Nacional de Estudos e Pesquisas Educacionais Anísio Teixeira - Inep:

A série histórica de resultados do Ideb se inicia em 2005, a partir de onde foram estabelecidas metas bienais de qualidade a serem atingidas não apenas pelo País, mas também por escolas, municípios e unidades da Federação. A lógica é a de que cada instância evolua de forma a contribuir, em conjunto, para que o Brasil atinja o patamar educacional da média dos países da Organização para a Cooperação $\boldsymbol{e}$ Desenvolvimento Econômico (OCDE). (BRASIL, 2018).

Conforme já indicava Afonso (2009), pode-se perceber o caráter hegemônico que está por trás das políticas de avaliações externas, as quais, dada a força e a imperatividade que lhes é atribuída pelas organizações internacionais, em prol de objetivos econômicos, sobrepõem-se aos governos e culturas locais, ignorando tudo aquilo que não pode ser objeto de vigilância e mensuração. Assim, a partir das afirmações do Inep, o governo evidencia a concepção de qualidade educacional à qual está vinculado, uma concepção que assume o alcance de metas numéricas firmadas por organizações internacionais como provas irrefutáveis de qualidade. A problemática 
encontra-se, todavia, no que está sendo ocultado pela lógica da evolução numérica para a elevação do Brasil ao patamar dos países da OCDE. Afinal, o que está em jogo é a negação de identidades locais, da possibilidade das sociedades periféricas se verem refletidas nas políticas públicas, em benefício de uma padronização estabelecida de fora, em nome de uma suposta qualidade educacional que se manifestaria no Ideb e não pela efetiva melhoria das condições em que os processos de aprendizagem e de ensino se dão, todos os dias, nas escolas.

Nessa perspectiva, destaca-se que os valores inerentes às avaliações externas incorporam e legitimam uma concepção classificatória do conhecimento, dos estudantes e das escolas. Configurase, então, o choque entre as avaliações limitadas a exames, que subalternizam conhecimentos, afrontam diferenças e desconsideram as experiências dos educandos, e a avaliação enquanto instrumento de uma educação libertadora, construída com a participação daqueles que usufruem do processo da educação, processo com o qual ela (a avaliação) compromete-se a melhorar, englobando, como consequência, o contexto dos estudantes para a construção de currículos significativos em uma escola promotora da democracia.

Dessa forma, as discussões propostas por este estudo visam refletir uma escola que almeja o respeito às diferenças, a superação de políticas como as avaliações externas e a esperança de uma sociedade mais justa, democrática e solidária, para a qual os ciclos poderão contribuir, na medida em que, contrariando a lógica tradicional da escola e da avaliação, herdeiras de funções sociais seletivas e excludentes, buscam uma avaliação que assume o papel de crescimento e melhoria da escola a partir de uma ótica interna (FREITAS, 2003). É nessa perspectiva que os diálogos e as problematizações construídos a partir da entrada no campo se estabeleceram, como o trabalho, a seguir, pretende demonstrar.

\section{A CONTRADIÇÃO MANIFESTA NA PRÁTICA: A IMPLEMENTAÇÃO DOS CICLOS EM NOVA IGUAÇU}

Por ser uma das redes de ensino estudadas na pesquisa Gabinete de Pesquisa em Desenvolvimento Curricular: estudo das propostas curriculares em ciclos, o município de Nova Iguaçu foi escolhido como foco deste trabalho. Trata-se da maior cidade da baixada fluminense, situada na região metropolitana, a mais importante, econômica e financeiramente, do Estado do Rio de Janeiro. Segundo o site QEdu ${ }^{2}$, a rede municipal possui um total de 135 escolas, com 63.880

\footnotetext{
${ }^{2}$ QEdu é um portal desenvolvido pela Meritt e Fundação Lemann. O portal declara que seu objetivo é "permitir que a sociedade brasileira saiba e acompanhe como está a qualidade do aprendizado dos alunos nas escolas públicas e cidades brasileiras" (LEMANN, 2018). Todavia, é importante situar que, de acordo com Freitas (2014), a Fundação Lemann se enquadra dentre os "reformadores empresariais da educação", atuando em disputa pelo controle do processo pedagógico
} 
matrículas, englobando creches, pré-escolas, ensino fundamental, educação de jovens e adultos e educação especial.

Visando melhor apresentar a forma como os ciclos foram compreendidos em Nova Iguaçu, foi fundamental a revisão de documentos publicados no período da implementação da proposta (final do ano de 1999 e início do ano 2000). A partir da análise dos documentos, se identificou um dicotômico precedente à instituição dos ciclos: a definição da "qualidade total” enquanto opção declarada para as políticas educacionais, isto no ano de 1999, ano anterior à adoção do novo regime na rede (DOCUMENTO 01/1999). Ou seja, a Secretaria de Educação adotou uma política de perspectiva empresarial e controladora, de um lado (qualidade total) e, de outro, propôs implementar a organização escolar em ciclos, sem que os documentos, como serão apresentados a seguir, definissem a proposta por meio da participação popular e de concepções curriculares e avaliativas orientadas pela dialogicidade.

O documento municipal No 01/1999, ao declarar a opção pela "qualidade total", não definiu seu significado e, embora a retórica insista na questão da qualidade, Paro (1999, p. 12) adverte que sua característica principal é a preocupação com a gerência, ou seja, o controle do trabalho alheio para dar conta das questões relacionadas à eficiência interna, tendo como objetivo a apropriação do excedente por meio da dominação do trabalhador. Com isso, em vez de diálogo (relação de troca entre sujeitos), instaura-se o gerenciamento mútuo, exercido pelo controle interpessoal que faz de todos objetos de vigilância uns dos outros (idem, 1999).

Deste modo, a qualidade total ensejada, baseia-se na promoção do maior esforço possível de cada docente, individualmente, e de cada escola, em particular, para tentar superar as demais. Nesta tentativa de superação, produz-se os que não são competentes e os que não se esforçaram o suficiente para tal. Esse sistema não funciona sem que se premiem (por meio de prestígio social, no mínimo) aqueles que são considerados como superiores. As diferenças de partida (econômicas, sociais) são ignoradas, em um sistema supostamente de oportunidades iguais (professores de uma mesma rede de ensino, que trabalhariam em escolas semelhantes, atendendo a uma mesma população).

Os ciclos foram instituídos em Nova Iguaçu por meio da Resolução SEMED No 007/99, de 03 de novembro de 1999, que tornou a nova forma de enturmação escolar obrigatória a partir do ano 2000. A proposta instituída, basicamente, eliminou a reprovação nos dois primeiros anos do

nas escolas, com a instituição de metodologias de mediação, processos de gestão verticalizados, dentre outras ações inspiradas pela lógica empresarial. 
ensino fundamental, já que a partir do terceiro ano a reprovação permanece possível, e anunciou a necessidade de flexibilização do tempo para aprendizagem dos estudantes, buscando evitar a excessiva fragmentação da estrutura curricular. Todavia, não foram encontrados indícios de um investimento concreto (em documentos orientadores, formação de professores etc.) que pudessem indicar ações efetivas nessa direção.

Com base nessas informações preliminares e considerando a orientação do município pela qualidade total, foi possível observar que a finalidade de reduzir os índices de evasão e repetência nas séries iniciais, conforme expresso nas considerações que fundamentam a decisão municipal (RESOLUÇÃO SEMED 07/99), constituiu um importante elemento na decisão pela implementação dos ciclos. Segundo Paro (2003) a queda desses índices, verificada como consequência dos ciclos, poderia ser percebida como melhoria na aprendizagem promovida pela escola.

A seguir, o conflito entre os ciclos e as avaliações externas na rede passa a ser estudado por meio das falas dos educadores.

\section{ENTRE OS CICLOS E AS AVALIAÇÕES EXTERNAS: ANÁLISE DAS PRÁTICAS AVALIATIVAS}

Buscando compreender a forma como os ciclos e as avaliações externas se efetivam atualmente na sala de aula, foram realizadas entrevistas semiestruturadas com três educadoras do município de Nova Iguaçu. Para escolha dessas profissionais, levou-se em consideração o fato de desempenharem funções que as tornam interlocutoras capazes de situar as intenções e práticas, tanto da gestão, quanto da docência, nos ciclos. Assim, foi entrevistada uma representante da SEMED e duas professoras com experiência há pelo menos dez anos com os ciclos em diferentes unidades escolares.

As entrevistas ocorreram entre os meses de novembro de 2016 e fevereiro de 2017, sendo construídas de modo a permitir uma conversa que perpassasse pelas concepções de avaliação adotadas para o trabalho com os ciclos, abordando, ainda, questões relativas às avaliações externas e sua influência sobre as práticas cotidianas, dentre outros pontos relevantes para a pesquisa. Todas as entrevistas ocorreram de forma individual, sendo a representante da SEMED entrevistada na própria Secretaria de Educação e as docentes, em suas salas de aula no horário anterior à chegada dos estudantes.

Durante as entrevistas, com perguntas que versavam sobre os reflexos do Ideb nas ações da SEMED, foi possível observar, na fala da representante da Secretaria, que a divulgação da baixa 
nota alcançada no ano de $2013^{3}$, levou à implantação de "pacotes" preparatórios para provas, ou seja, submeteram-se os docentes cujas turmas realizariam os exames, a programas de capacitação voltados exclusivamente ao treino para tais, o que incluiu o oferecimento dos materiais para “exercitar" os estudantes até a data da prova. A esse respeito, Dora ${ }^{4}$, representante da SEMED, afirmou:

Implementamos um programa de formação para os professores do $4^{\circ}$ e $5^{\circ}$ ano, que é o “Aprova Brasil”, da editora Moderna, se não me engano. Então nós compramos um pacote de materiais e de formação e até o melhoramento nas notas em 2015 se deu por conta disso e do investimento que a gente fez na alfabetização através do PNAIC. Então nós tivemos alunos melhores no $4^{\circ}$ e $5^{\circ}$ ano por conta dessa formação específica trazida pela editora moderna com esse pacote que foi comprado. Foi um pacote apenas para o $4^{\circ}$ e $5^{\circ}$ ano porque entendemos que o ciclo já tinha o trabalho do PNAIC. No pacote se tinha a formação acadêmica e o material didático para ser trabalhado com o aluno, preparando para a prova. $\mathrm{Na}$ análise do material percebe-se que ele foi todo pensado e organizado de acordo com os descritores que, por sua vez, estão vinculados com os direitos de aprendizagem do PNAIC. Então tem uma linha de continuidade. (GESTORA DORA, novembro de 2016).

Observando a fala de Dora, é possível perceber que ela entende a medida adotada pela rede como acertada, uma vez que atingiu o objetivo de preparar os alunos especificamente para a realização das provas, aumentando do Ideb do município. Todavia, o que se deve questionar é que medidas poderiam contribuir efetivamente para o aumento da qualidade da educação e não apenas para o aumento de índices. Nesse sentido, pensar no oferecimento de melhores condições de trabalho ou na introdução de mudanças na maneira de ensinar, parecem medidas mais efetivas para o alcance da qualidade, uma vez que os "pacotes" incidem apenas na alteração pontual de indicadores.

Questionadas sobre as possíveis interferências geradas pelas avaliações externas sobre os processos de avaliação cotidianos do ciclo, as duas professoras entrevistadas declararam não existir qualquer influência e mostraram-se contrárias ou resistentes às avaliações padronizadas que compõem o Ideb.

\footnotetext{
${ }^{3}$ A presente pesquisa foi iniciada no ano de 2015, portanto, a nota do Ideb municipal mais recente correspondia a do ano de 2013, sobre o qual as ações municipais, naquele período, se desdobraram.

${ }^{4}$ Para manter o sigilo das fontes, os nomes das pessoas entrevistadas são fictícios.
} 
Quando perguntada sobre o que a Provinha Brasil ${ }^{5}$ representa, uma das professoras expôs:

Que questão difícil essa...eu não sei...pera aí, deixa eu pensar aqui...o que a Provinha Brasil representa? É...eu sou contra a avaliação externa, eu não gosto disso, por exemplo, essa minha turma desse ano que terminou, eles tiveram um avanço impressionante e eu sei que não foi refletido na Provinha Brasil, porque eu peguei uma turma que não estava alfabetizada e terminei com eles, em peso, alfabetizados e eu sei que isso não vai aparecer, porque os conteúdos que estão lá não são especificamente o que eu consegui trabalhar com eles. Claro, eu gostaria que eles tivessem obtido resultados dentro do esperado, mas não tem como, porque a realidade é completamente diferente do que está lá. É...enfim, falar o que eu considero da Provinha Brasil, eu acho que é mais uma avaliação externa, que não reflete de fato os avanços de uma turma. A gente não consegue ver nessas avaliações a individualidade, o verdadeiro crescimento que tem [as crianças]. Nas diagnoses que faço, no meu acompanhamento, eu percebo o avanço deles, ou não, onde eles precisam melhorar, coisa que eu não vou conseguir ver na Provinha Brasil, por ter um nível estabelecido para todos, não adianta que isso não vai aparecer na individualidade do aluno, né? Naquele momento tenso de fazer uma prova...e o ciclo não tem prova, como eu disse, eles são avaliados por relatório, a gente aplica prova porque o professor quer, não por algo que seja do município, porque até o $3^{\circ}$ ano você não precisa aplicar prova... então, eles fazem uma prova que não estão acostumados, de marcar X em questão e eu não acho que marcação da resposta certa seja reconhecer o aprendizado de um aluno. Então é isso, é mais uma burocracia que eu vejo, e não de fato um instrumento de verificação de aprendizagem de um aluno, eu não consigo encarar dessa forma. (PROFESSORA TAMIRES, fevereiro de 2017.)

O que se observa na fala de Tamires é uma concepção de avaliação distinta das provas padronizadas, ela percebe as avaliações externas como descoladas do processo de aprendizagem que vem sendo desenvolvido. Tamires diz que a avaliação pretende ajudar a compreender como os alunos e alunas estão aprendendo e progredindo, pois só assim é possível introduzir correções, propor ações alternativas e reforçar determinados aspectos.

O desenvolvimento das entrevistas evidenciou o conflito, demonstrado pelas docentes nas entrevistas, de que embora se posicionem contrárias às avaliações externas e asseverem que estas não são um instrumento que contribua para o acompanhamento efetivo da aprendizagem, poderiam

\footnotetext{
${ }^{5}$ Instrumento de avaliação externa que afeta diretamente o ciclo de alfabetização - composto pelos três primeiros anos do ensino fundamental, única etapa da escolarização organizada em ciclos no município estudado. A Provinha Brasil é aplicada às crianças matriculadas no $2^{\circ}$ ano do ensino fundamental, sendo composta por testes de Língua Portuguesa e de Matemática (BRASIL, 2018).
} 
contribuir para que os estudantes se acostumassem a outro modelo de avaliação. Com isso, as professoras afirmaram produzir, por iniciativa individual, atividades que simulam as provas. A esse respeito, declararam:

Não acredito muito nessa Provinha Brasil não. Faço, como eu já falei, porque eu quero que eles tenham a experiência nesse modelo, mas essa avaliação para mim é muito superficial.[...] Referente a essa Provinha Brasil, eu acho que tudo é válido, até porque as provas que nós fazemos, referentes a vestibular, a concursos, são assim. Então não descarto não, só não acho que ela seja o "top de linha" para avaliar um aluno, mas não questiono assim não...acho que tudo é válido. [...] A Provinha Brasil representa pra mim uma modalidade diferenciada que não é a mesma que eu costumo usar, não mesmo, até por conta de material, essas coisas todas, tempo também. Mas eu acho que é outra metodologia, outra forma para a criança conhecer o trabalho, para não ficar tão alienada do mundo né? Saber que é assim que acontece no mundo, que as avaliações são feitas assim. (PROFESSORA MARIANA, fevereiro de 2017.)

Nesse último ano, eu não consegui, por exemplo, dar simuladinhos de Prova Brasil para eles. Isso não teve como eu fazer porque era uma turma muito fraca. Eu terminei o ano com praticamente todos alfabetizados, só mesmo quem tinha algum comprometimento, apesar de não ter laudo, não conseguiu atingir. Mas eu não consegui trabalhar não, não teve adaptação voltada para o Prova Brasil não. Nos outros anos sim, eu consegui trabalhar questões, aplicar conteúdos, por exemplo, simuladinhos da Prova com eles. E esses simulados sempre foram feitos por conta própria, até em relação a impressão de materiais, sempre fui eu, não era a escola que fornecia não. (PROFESSORA TAMIRES, fevereiro de 2017.)

O que as docentes afirmaram é que há mudanças em suas práticas educativas cotidianas a partir da institucionalização das avaliações externas, uma vez que, mesmo atuando e compreendendo a avaliação na perspectiva dos ciclos, consideram importante destinar momentos em suas aulas para as avaliações externas.

Nesse sentido, torna-se imprescindível refletir sobre os riscos que a imposição das avaliações externas representa para as conquistas de uma avaliação continuada. Tomar a avaliação externa como representação do que ocorreu no processo de aprendizagem é afirmar que os resultados da aprendizagem são observáveis em tais provas, o que temos visto que não é realidade.

Quando se assume uma perspectiva educacional progressista, na qual os ciclos se inserem, o que se pretende, conforme apresenta Arroyo (2007, p. 18), é superar a estreita concepção de ensino que ainda é "resquício de uma visão mercantilizada, na qual a escola avalia pelo critério 
reducionista de mérito e de fracasso nos concursos, nos vestibulares, nas provas, no domínio das competências e habilidades que o mercado segmentado e escasso exige".

Analisando ainda as falas das educadoras, é possível perceber que não há uma percepção, destas educadoras, da política que as avaliações externas representam em seu conjunto. Há uma crítica às avaliações externas, no que se refere ao que elas pouco dizem sobre os processos de aprendizagem e de que não são adequadas às necessidades da organização em ciclos, mas não há uma visão sobre a responsabilização e a desqualificação da escola pública que as mesmas provocariam, ao menos conforme entendem os estudos aqui apresentados (ESTEBAN e FETZNER, 2015; FREITAS, 2012). Nada obstante, deve-se destacar que as falas docentes também evidenciaram ações que se alinham a uma concepção de avaliação continuada, potencializando um possível processo de mudança alicerçado nas próprias escolas.

Espera-se que as questões elencadas neste trabalho possam ajudar a perceber a relação controversa entre as avaliações propostas em organizações escolares em ciclos e aquelas que decorrem de políticas outras, distantes da necessidade de uma educação a serviço do aprender a viver com a maior plenitude individual e social que a história possibilita (PARO, 2011), o que não se dará com a padronização de conteúdos e treinamentos para as avaliações externas, mas que pode ser facilitado a partir da autonomia docente, enquanto responsável pela mediação nos processos de aprendizagem.

\section{CONSIDERAÇÕES FINAIS}

A pesquisa buscou compreender a relação entre a enturmação em ciclos e as avaliações externas, presentes no cotidiano de uma escola da rede municipal de Nova Iguaçu. Este cruzamento de políticas é potencializado pelo Programa Nacional Alfabetização na Idade Certa, à medida em que incorpora a organização em ciclos nos três primeiros anos do ensino fundamental e, ao mesmo tempo, institui a Provinha Brasil (em 2013) e a primeira avaliação externa para o $3^{\circ}$ ano de escolaridade, a ser implementada em 2014.

Os estudos realizados percebem os ciclos e as avaliações externas como políticas em conflito. Os ciclos, porque afirmam a capacidade permanente de aprendizagem, a necessidade de contextualização dos estudos na vida cotidiana e a liberdade de organização da aula (no que se refere ao currículo, à didática e aos processos avaliativos) por parte do docente, da escola e dos estudantes. De outra perspectiva, as avaliações externas, enquanto política de controle e responsabilização, incentivam o ranqueamento das escolas, a padronização e a homogeneidade. 
Mais especificamente, no que se refere às práticas avaliativas, os ciclos privilegiam as trocas, a heterogeneidade, o acompanhamento coletivo do processo, a continuidade das aprendizagens, enquanto as avaliações externas trabalham com a necessidade de classificar e homogeneizar o conhecimento, as pessoas e as redes, em nome, no Brasil, de um suposto direito de aprendizagem.

O estudo também verificou que a mescla dos ciclos com propostas de base empresarial já se deram no município estudado desde a implementação, em 1999, da qualidade total como compromisso. O estudo empírico junto a três educadoras (gestora Dora e professoras Tamires e Mariana) demonstrou que consideram o treino para as avaliações externas uma prática apropriada, isto na medida em que a gestora apoiou a aquisição de programas de treinamento e as duas professoras entrevistadas, mesmo afirmando-se inicialmente contrárias a tais avaliações, indicaram destinar momentos de sua prática à preparação para as provas. Com isso, há indícios de uma preocupação originada pelas próprias docentes para que os estudantes obtenham êxito nesses exames. Infere-se, portanto, que a avaliação externa provoca mudanças nas práticas cotidianas dessas educadoras com o treinamento, quando possível, para as provas.

Percebeu-se que, embora exista um tempo destinado ao preparo para as provas padronizadas, outras práticas avaliativas, mais contínuas e processuais, são predominantes na ação cotidiana, gerando resultados favoráveis ao processo de ensino e aprendizagem. Portanto, o que se constatou foram conhecimentos sobre o ato educativo que permitem às entrevistadas questionar a eficácia das avaliações externas e utilizar outros parâmetros e instrumentos para o desenvolvimento da escola organizada em ciclos, fundada no reconhecimento das diferenças de aprendizagem em suas formas e tempos. 


\section{REFERÊNCIAS}

AFONSO, A. J. Nem tudo o que conta em educação é mensurável ou comparável: Crítica à accountability baseada em testes estandardizados e rankings escolares. Revista Lusófona de Educação, Lisboa, n.13, p.13-29, 2009.

ARROYO, M. G. Ciclos de Formação: O que pesquisar e refletir? In KRUG, Andréa R. F. (org.) Ciclos em Revista: implicações curriculares de uma escola não seriada, v. 2, Rio de Janeiro: Wak Editora, p. 17-34, 2007.

BALL, S. J. Performatividades e fabricações na economia educacional: rumo a uma sociedade performativa.Educação \& Realidade, n. 35, v. 2, p. 37-55, mai.-ago., 2010.

BRASIL. Ministério da Educação (MEC). Programa Nacional Alfabetização na Idade Certa (PNAIC). Brasília, 2018. Disponível em: http://portal.mec.gov.br/index.php?option=com_docman\&view=download\&alias=11268-gt-capitais-pnaic-apresentacao21062012-pdf\&Itemid=30192 Acesso em: 23/07/2018.

. Ministério da Educação. Instituto Nacional de Estudos e Pesquisas Educacionais Anísio Teixeira (INEP). Provinha Brasil. Brasília, 2018. Disponível em: http://portal.Inep.gov.br/provinha-brasil Acesso em: 10/06/2018.

Ministério da Educação. Instituto Nacional de Estudos e Pesquisas Educacionais Anísio Teixeira. Ideb. Brasília, 2018. Disponível em: http://portal.Inep.gov.br/ideb Acesso em: 09/06/2018.

Ministério da Educação. Instituto Nacional de Estudos e Pesquisas Educacionais Anísio Teixeira. Metas educacionais. Brasília, 2018. Disponível em: http://portal.Inep.gov.br/metas-educacionais Acesso em: 09/06/2018.

Ministério da Educação. Ideb-Apresentação. Brasília, 2018. Disponível em: http://portal.mec.gov.br/conheca-o-ideb Acesso em: 09/06/2018

Ministério da Educação. Conselho Nacional de Educação. Câmara de Educação Básica. Resolução no 7: Fixa Diretrizes Curriculares Nacionais para o Ensino Fundamental de 9 (nove) anos. Brasília, 2010. Disponível em: http://portal.mec.gov.br/dmdocuments/rceb007_10.pdf Acesso em: 23/07/2018.

ESTEBAN, M. T.; FETZNER, A. R. A redução da escola: a avaliação externa e o aprisionamento curricular. Educar em Revista, Curitiba, Edição Especial n. 1. 2015, p. 75-92.

FETZNER, A. R. Da avaliação classificatória às práticas avaliativas participativas: esta migração é possível? In: FETZNER, A. R. (org.). Ciclos em Revista: avaliação: desejos, vozes, diálogos e processos, vol. 4. Rio de Janeiro: Wak Editora. 2008, p. 143-158.

FREIRE, P. Educação como prática da liberdade. 31 ed. Rio de Janeiro: Paz e Terra, 2008a.

FREITAS, L. C. de. Os reformadores empresariais da educação e a disputa pelo controle. Educ. Soc., Campinas, v. 35, nº 129 , p. 1085-1114, out.-dez., 2014.

Os reformadores empresariais da educação: da desmoralização do magistério à destruição do sistema público de educação. Educ. Soc., Campinas, v. 33, n. 119, p. 379-404, abr.-jun. 2012.

Ciclos, seriação e avaliação: confronto de lógicas. 1. Ed. São Paulo: Moderna, 2003.

KRUG, A. R. Ciclos de Formação: uma proposta transformadora. 2. ed. Porto Alegre: Mediação, 2006.

PARO, V. H. Progressão continuada, supervisão escolar e avaliação externa: implicações para a qualidade do ensino. Revista Brasileira de Educação, 2011, v. 16, n. 48, set-dez, p. 695-716.

Reprovação escolar: renúncia à educação. São Paulo: Xamã, 2003.

Parem de preparar para o trabalho! Reflexões acerca dos efeitos do neoliberalismo sobre a gestão e o papel da escola básica. In: FERRETTI, C. J. et al. (Orgs.). Trabalho, formação e currículo: para onde vai a escola. São Paulo: Xamã, 1999, p. 101-120.

PREFEITURA MUNICIPAL DE NOVA IGUAÇU. Resolução SEMED 007/99: Estabelece as normas gerais do Sistema de Progressão da Rede Escolar da Secretaria Municipal. Nova Iguaçu: Jornal de Hoje, 13 de nov. 1999.

Documento 01/1999: Estabelece o objetivo da Secretaria Municipal de Educação para o ano de 1999. Nova Iguaçu, 1999.

FUNDAÇÃO LEMANN. QEDU. Nova Iguaçu. 2018. Disponível em: http://www.qedu.org.br/cidade/2783-nova-iguacu/censo-

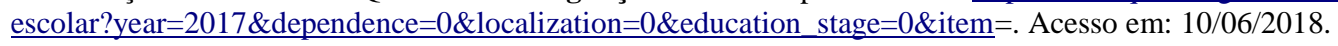

RAVITCH, D. Vida e morte do grande sistema escolar americano: como os testes padronizados e o modelo de mercado ameaçam a educação. Porto Alegre: Sulina, 2011.

SACRISTÁN, J. G; GÓMEZ, A. I. P. Compreender e transformar o ensino. 4. ed. Porto Alegre: ArtMed, 1998.

SAUL, A. M. Avaliação emancipatória: desafio à teoria e à prática de avaliação e reformulação de Currículo. 7. ed. São Paulo: Cortez, 2006. 


\section{RESUMO}

Este artigo discute a relação entre a enturmação escolar em ciclos e as avaliações externas, políticas presentes nas salas de aula e em permanente conflito político, teórico e pedagógico. Busca-se compreender como os ciclos, enquanto projeto de democratização escolar, e as avaliações externas, orientadas pela mensuração e pelo controle, coexistem em uma escola da rede pública municipal de Nova Iguaçu, no estado do Rio de Janeiro. Trata-se de uma pesquisa qualitativa que realiza estudos bibliográficos, documentais e entrevistas com três educadores do município. Como resultado, observaram-se as interferências das avaliações externas sobre as práticas docentes e a persistência de algumas práticas avaliativas que se sustentam, apesar destas interferências.

Palavras-chave: Organização escolar em ciclos. Avaliações externas. Avaliação escolar.

\section{EXTERNAL EVALUATIONS IN SCHOOLS ORGANIZED IN CYCLES: A SCHIZOPHRENIA IN THE EDUCATIONAL SPACE}

\section{ABSTRACT}

This article discusses the relationship between the schooling in cycles and the external evaluations, policies present in the classrooms and in permanent political, theoretical and pedagogical conflict. It seeks to understand how the cycles, the project of school democratization, and external evaluations, oriented by measurement and control, coexist in a of the public school of Nova Iguaçu city, in Rio de Janeiro. It is a qualitative research that performs bibliographic, documentary studies and interviews with three educators of the city. As a result, the interferences of external evaluations on the teaching practices and the persistence of some of the evaluation practices that are sustained, despite these interferences.

Keywords: School organization in cycles. External evaluations. School evaluation.

\section{EVALUACIONES EXTERNAS EN LAS ESCUELAS ORGANIZADAS EN CICLOS: UNA ESQUIZOFRENIA EN EL ESPACIO EDUCATIVO}

\section{RESUMEN}

Este artículo discute la relación entre la enturbación escolar en ciclos y las evaluaciones externas, políticas presentes en las aulas y en permanente conflicto político, teórico y pedagógico. Se busca comprender cómo los ciclos, como proyecto de democratización escolar, y las evaluaciones externas, orientadas por la medición y el control, coexisten en una escuela de la red pública municipal de Nova Iguaçu, en el estado de Río de Janeiro. Se trata de una investigación cualitativa que realiza estudios bibliográficos, documentales y entrevistas con tres educadores del municipio. Como resultado, se observaron las interferencias de las evaluaciones externas sobre las prácticas docentes y la persistencia de algunas prácticas de evaluación que se sostienen, a pesar de estas interferencias.

Palabras clave: Organización escolar en ciclos. Evaluaciones externas. Evaluación escolar. 